Hydrol. Earth Syst. Sci., 14, 613-626, 2010

www.hydrol-earth-syst-sci.net/14/613/2010/

(C) Author(s) 2010. This work is distributed under

the Creative Commons Attribution 3.0 License.

\title{
A comparison of ASCAT and modelled soil moisture over South Africa, using TOPKAPI in land surface mode
}

\author{
S. Sinclair and G. G. S. Pegram \\ Department of Civil Engineering, University of KwaZulu-Natal, Durban, South Africa \\ Received: 24 October 2009 - Published in Hydrol. Earth Syst. Sci. Discuss.: 3 December 2009 \\ Revised: 26 March 2010 - Accepted: 26 March 2010 - Published: 6 April 2010
}

\begin{abstract}
In this paper we compare two independent soil moisture estimates over South Africa. The first estimate is a Soil Saturation Index (SSI) provided by automated real-time computations of the TOPKAPI hydrological model, adapted to run as a collection of independent $1 \mathrm{~km}$ cells with centres on a grid with a spatial resolution of $0.125^{\circ}$, at $3 \mathrm{~h}$ intervals. The second set of estimates is the remotely sensed ASCAT Surface Soil Moisture product, temporally filtered to yield a Soil Wetness Index (SWI). For the TOPKAPI cells, the rainfall forcing used is the TRMM 3B42RT product, while the evapotranspiration forcing is based on a modification of the FAO56 reference crop evapotranspiration $\left(\mathrm{ET}_{0}\right)$. $\mathrm{ET}_{0}$ is computed using forecast fields of meteorological variables from the Unified Model (UM) runs done by the South African Weather Service (SAWS); the UM forecast fields were used, because reanalysis is not done by SAWS. To validate these $\mathrm{ET}_{0}$ estimates we compare them with those computed using observed meteorological data at a network of weather stations; they were found to be unbiased with acceptable scatter. Using the rainfall and evapotranspiration forcing data, the percentage saturation of the TOPKAPI soil store is computed as a Soil Saturation Index (SSI), for each of 6984 unconnected uncalibrated TOPKAPI cells at $3 \mathrm{~h}$ time-steps. These SSI estimates are then compared with the SWI estimates obtained from ASCAT. The comparisons indicate a good correspondence in the dynamic behaviour of SWI and SSI for a significant proportion of South Africa.
\end{abstract}

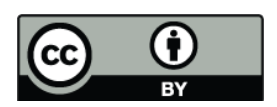

Correspondence to: S. Sinclair (sinclaird@ukzn.ac.za)

\section{Introduction}

Up-to-date estimates of soil moisture are of interest across a wide range of disciplines, including numerical weather prediction, agricultural applications and flood modelling. The current soil moisture state is a good indicator of flash flood potential on small catchments with a short response time but is not easily measured. There is significant global interest in estimating soil moisture from satellite platforms (e.g. Wagner et al., 1999; Njoku et al., 2003; Kerr et al., 2001). One of the major challenges facing providers of soil moisture products is validation. This is mainly due to the limited availability and coverage of in situ observation networks (Albergel et al., 2009). Several authors have pursued alternative techniques of validation, inter alia correlations between river flows and soil wetness (Scipal et al., 2005) and assimilation of remotely sensed soil moisture estimates into a water balance model (Crow, 2007).

One outcome of a current South African Water Research Commission funded project on soil moisture estimation, is an automated modelling system that produces country-wide estimates of soil moisture state at a $3 \mathrm{~h}$ time-step on a $0.125^{\circ}$ spatial grid over South Africa. The key focus of this product is to provide a proof of concept for operational use by the South African Weather Service (SAWS) in their national Flash Flood Guidance (FFG) system, which will be an implementation of the system described by Ntelekos et al. (2006). There are numerous other fields (other than FFG) such as crop modelling, and drought monitoring where soil moisture estimates could prove beneficial.

In this paper, we describe a soil moisture modelling process, which includes a technique for determining reference crop evapotranspiration (ET ${ }_{0}$, Allen et al., 1998) using forecast fields of meteorological variables from a numerical weather prediction model, run operationally by the SA

Published by Copernicus Publications on behalf of the European Geosciences Union. 
Weather Service (SAWS, see Sect. 2). We continue by presenting an overview of the soil moisture modelling system (Sect. 3), which is based on a local implementation of the TOPKAPI hydrological model (Liu and Todini, 2002; Vischel et al., 2008a,b) adapted to run in Land Surface Modelling (LSM) mode. In Sect. 3 we also present some examples of the soil moisture simulations produced by the TOPKAPI model, while in Sect. 4 we describe a remote sensing soil moisture retrieval product (Bartalis et al., 2008) from the ASCAT instrument on-board EUMETSAT's METOP polar orbiting satellite. In that section we also present and discuss the results of comparisons made between the two independent soil moisture estimates at selected locations in South Africa. In Sect. 5 we investigate possible reasons for the poor correspondence found in some parts of the country, while in Sect. 6 we draw conclusions based on the results presented in the paper.

\section{Estimation of evapotranspiration}

Evapotranspiration is widely accepted as an important component in the water balance at a range of different space and time scales but is difficult to measure directly over large areas at frequent time intervals (e.g., McCabe and Wood, 2006). This is particularly important in Southern Africa, where a large proportion of the rainfall is lost through evaporative processes, resulting in a country-wide runoff/rainfall ratio in the order of $10 \%$. Since evapotranspiration is driven by the surface energy balance (Eq. 1), its spatial distribution is determined by the spatial behavior of the components of this energy balance and can therefore be quite complex (particularly at detailed space and time scales). The surface energy balance on a control volume, including the surface vegetation and the first few centimeters of soil, can typically (e.g., $\mathrm{Su}, 2002$ ) be written as a scalar equation:

$R_{n}=\lambda \mathrm{ET}_{a}+H+G$

where $R_{n}$ is the net radiation flux into the control volume, $H$ is the sensible heat flux out of the control volume into the air stream, $G$ is the heat flux out of the control volume into the ground, $\mathrm{ET}_{a}$ is the actual evapotranspiration from the control volume to the air and $\lambda$ is the latent heat of vaporization of water.

As part of a South African Water Research Commission funded project, focused on soil moisture estimation in Southern Africa (using local hydrological modelling and remote sensing), a spatial grid of reference crop evapotranspiration estimates $\left(\mathrm{ET}_{0}\right)$ is routinely produced using the methodology described in Allen et al. (1998). ET $\mathrm{ET}_{0}$ can be related to $\mathrm{ET}_{a}$ through the application of location and season dependent land cover and water stress coefficients. The approach taken here is detailed in Sect. 2.4.
Forecasts (from $0-24 \mathrm{~h}$ ahead) of the meteorological variables required for $\mathrm{ET}_{0}$ estimation are obtained from the SAWS Unified Model (UM) runs, from which an hourly estimate of $\mathrm{ET}_{0}$ is computed for each model grid cell. The resulting $\mathrm{ET}_{0}$ estimates are produced on a $0.11^{\circ}$ grid, matching that of the UM. This $\mathrm{ET}_{0}$ product is used as forcing data for isolated cells of the TOPKAPI distributed hydrological model, which are used to compute distributed estimates of soil moisture (Sect. 3).

\subsection{Description of data sources used to compute $\mathbf{E T}_{\mathbf{0}}$}

This section describes the sources of data used to produce and validate the spatially distributed $\mathrm{ET}_{0}$ estimates. This is done with two purposes in mind. First, we wanted to obtain some observations of temperature, relative humidity, wind speed and radiation at Automatic Weather Stations, so that we could obtain reference values of point $\mathrm{ET}_{0}$ estimates. Because these are too sparse for our purposes, we need to produce a spatial estimate of $\mathrm{ET}_{0}$. To evaluate the accuracy of the spatial estimates, we first compare them with the point estimates. We had intended to condition the UM spatial estimates of meteorological variables onto the observations using a technique called conditional merging involving Ordinary Kriging (Sinclair and Pegram , 2005), but found that this was not necessary because the spatial estimates of $\mathrm{ET}_{0}$ were unbiased compared to the point estimates.

\subsubsection{Automatic Weather Station Network}

The SAWS Automatic Weather Station (AWS) network provides surface meteorological information to a central datacollection facility. The network is shown in Fig. 1, indicating the relatively sparse coverage over the country (164 stations in 1.2 million $\mathrm{km}^{2}$ ). Due to this sparse coverage the weather stations cannot be used as the sole source of information for producing spatial $\mathrm{ET}_{0}$ estimates, as they are unable to efficiently sample the spatial detail of the meteorological fields. We use them to make comparisons with the estimates we obtain from the UM forecasts, with which they are shown (Sect. 2.3) to be unbiased and relatively highly correlated.

The meteorological variables measured at each station which are relevant to the computation of $\mathrm{ET}_{0}$ are: temperature, relative humidity and wind speed. No radiation measurements are made at these stations, so an alternative was sought - see Sect. 2.1.3.

\subsubsection{Unified model}

SAWS has recently (late 2006) installed the UK Met Office's UM, which is run at a grid resolution of $0.11^{\circ}$ with 401 rows and 601 columns, covering Africa and the surrounding oceans south of the Equator. The bounding coordinates of the grid are defined by $10^{\circ} \mathrm{W}$ to $56^{\circ} \mathrm{E}$ and $0^{\circ} \mathrm{S}$ to $44^{\circ} \mathrm{S}$. The model is run twice daily in a number of different configurations. Assimilation of observed data and boundary 
SAWS Automatic Weather Stations

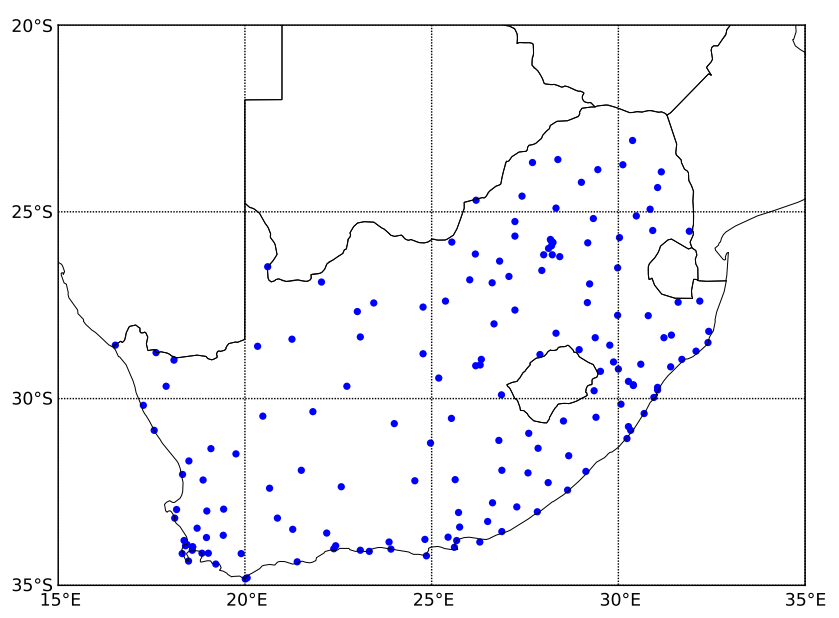

Fig. 1. Plot showing the locations of the South African Weather Services (SAWS) current automatic weather stations. Other meteorological stations exist, but are either manually read, or are operated by different organizations. The coverage is sparse, with only 164 stations in 1.2 million $\mathrm{km}^{2}$.

conditions occur at 00:00 UTC and 12:00 UTC, and hourly weather forecasts are produced out to $48 \mathrm{~h}$ from each model run time. The model fields used in this study are the 00:00 UTC assimilation fields and the resulting hourly forecast fields out to $23 \mathrm{~h}$ ahead. As demonstrated in Sect. 2.3, we were able to satisfy ourselves that the model forecasts of the major environmental variables resulted in sufficiently accurate estimates of $\mathrm{ET}_{0}$ to justify the use of the forecast fields in our real-time product.

\subsubsection{Solar radiation}

Because it is difficult to find operational surface radiation observations at an hourly (or even daily) frequency in South Africa, solar radiation estimates based on Meteosat data were selected. The data products are obtained from the Land Surface Analysis Satellite Application Facility (LSA-SAF http://landsaf.meteo.pt) and are disseminated in real time at $30 \mathrm{~min}$ intervals via the EUMETCast system, which we download in real-time to our server, under a research agreement with EUMETSAT.

The advantage of this product, in comparison to sparse surface AWS observations, is that a detailed spatial coverage is available over large areas at frequent intervals. Figure 2 shows a typical map of the estimated solar radiation flux for Africa, South of the equator. Clouds are clearly implied, in areas coloured green through to blue, indicating various degrees of radiation occlusion.

To the best of the authors' knowledge, the LSA-SAF DSSF product has only been validated under European conditions, (LSA-SAF, 2006) where it was shown to be unbiased, and its applicability in Southern Africa was not known

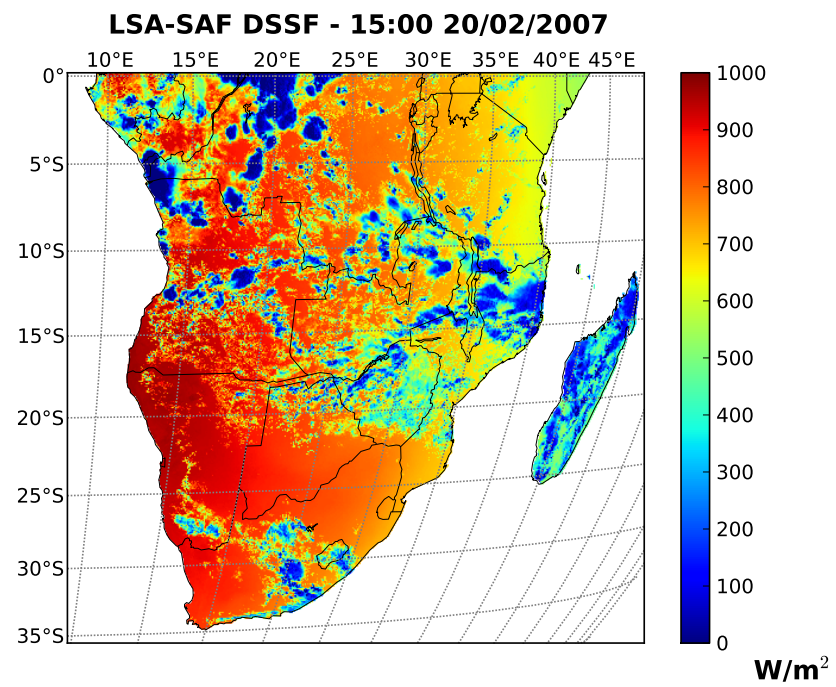

Fig. 2. Example of the LSA-SAF DSSF product for Southern Africa. The data are available at half hour intervals, via the EUMETCast system.

before this study, but similar results were a reasonable expectation. As an exercise to increase confidence in the estimates, a basic comparison with some observed data was carried out.

A time series of solar radiation data collected from the CSIR study catchments $\left(30.67^{\circ} \mathrm{S}, 29.19^{\circ} \mathrm{E}\right)$, situated at the Mistley-Canema Estate (Mondi Forests) in the Seven Oaks district, approximately $70 \mathrm{~km}$ from Pietermaritzburg was obtained (C. Everson, 2008, personal communication). These observed data were compared with the LSA-SAF estimates at the same location and times. Figure 3 shows a comparison between the measured and estimated solar radiation over a period of 5 days between 20 and 24 February 2007. This initial test of applicability is very encouraging, with the coefficient of determination $\left(R^{2}\right)$ for the best fit linear regression line equal to 0.918 . There is evidently good agreement in the absence of cloud and more scatter when cloud is present we ascribe some of those differences to mistiming as there is negligible bias overall.

\subsection{Methodology for computing $\mathbf{E T}_{0}$ from meteorological variables}

The method we use to estimate real-time actual evapotranspiration $\left(\mathrm{ET}_{a}\right)$ is indirectly by combining its estimation with that of Soil Moisture in the TOPKAPI cell soil store, by forcing it with TRMM rainfall and reference crop $\mathrm{ET}_{0}$. The alternative would be to estimate $\mathrm{ET}_{a}$ independently using surface atmospheric observations and applying the principle of conservation of mass. However, it is difficult to solve the Surface Energy Balance directly for $\mathrm{ET}_{a}$ without directly measuring all of the radiative fluxes (for an example of the complexities of detailed measurements see Savage, 2009; Savage et al., 2009), so we work with the TOPKAPI cell. The first step in 


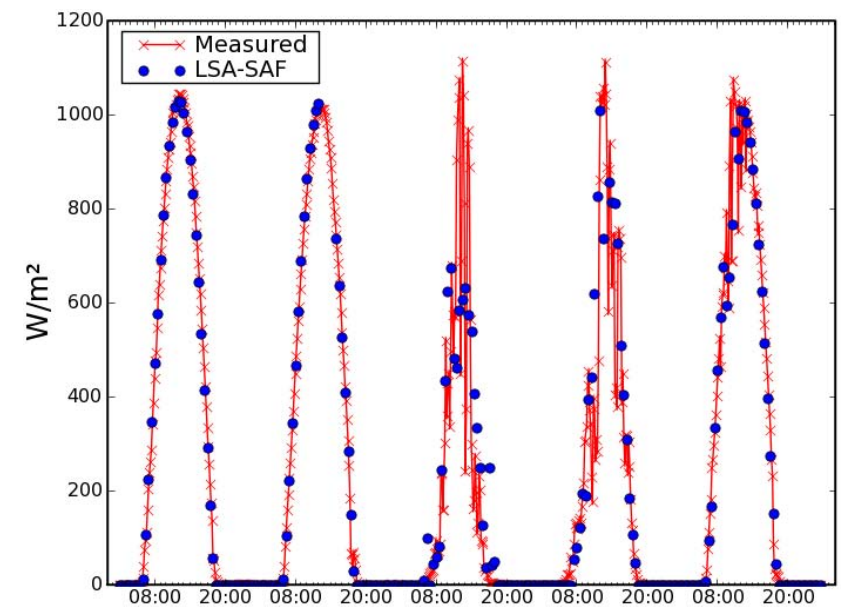

Fig. 3. Comparison of observed solar radiation with observations in KwaZulu-Natal, South Africa made by the CSIR (C. Everson, personal communication, 2008). The blue points are the half-hourly DSSF estimates from the LSA-SAF product and the red crosses are the data observed at the ground, measured at $12 \mathrm{~min}$ intervals.

the calculation chain is the estimation of $\mathrm{ET}_{0}$ at each $\mathrm{UM}$ grid point using the Penman-Monteith equations recommended in FAO56 (Allen et al., 1998). The result is an estimate of evapotranspiration for a well watered (sufficient soil water to meet maximum demand) reference crop defined as

\section{A hypothetical reference crop with an assumed crop height of $0.12 \mathrm{~m}$, a fixed surface resistance of $70 \mathrm{~s} \mathrm{~m}^{-1}$ and an albedo of 0.23 - Allen et al. (1998)}

An implementation of the hourly algorithm described in Allen et al. (1998) has been developed for this study using the Python programming language. This code has been applied to process SAWS model (and alternatively Automatic Weather Station) data and produces an estimate of $\mathrm{ET}_{0}$ at each grid point in hourly increments. The hourly estimates of $\mathrm{ET}_{0}$ (an example of an instantaneous estimate of subcontinent-wide values is shown in Fig. 4) can be summed to produce a daily total, an example of which appears in Fig. 5, for illustration purposes. In real time operation, we use 3 hourly total evapotranspiration to force the TOPKAPI soil water calculations.

The FAO56 "reduced form" Penman-Monteith equation applied to the surface control volume is given in Eq. (2) below:

$\mathrm{ET}_{0}=\frac{0.408 \Delta\left(R_{n}-G\right)+\gamma \frac{C_{n}}{T+273} u_{2}\left[e_{s}-e_{a}\right]}{\Delta+\gamma\left(1+C_{d} u_{2}\right)}$

where $\Delta$ is the slope of the saturation vapor pressure versus temperature curve, $R_{n}$ is the net radiation influx, $G$ is the soil heat flux, $\gamma$ is the pyschrometric constant, $T$ is the temperature, $u_{2}$ is the wind speed at $2 \mathrm{~m}$ height, $e_{s}$ is the saturation
Reference Crop Evapotranspiration - 12:00 20/02/2007

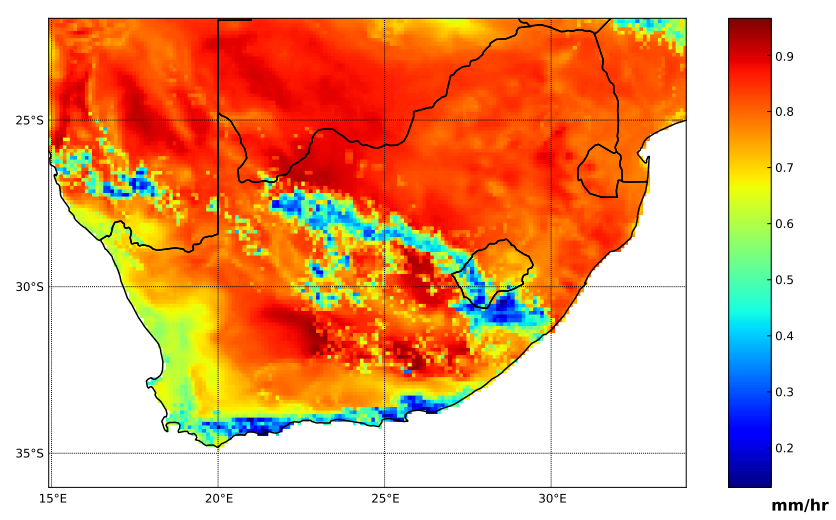

Fig. 4. An hourly estimate of $\mathrm{ET}_{0}$ computed from NWP forecast data and LSA-SAF radiation estimates.

vapor pressure, $e_{a}$ is the actual vapor pressure. The coefficients $C_{n}$ and $C_{d}$ vary with the aerodynamic and bulk surface resistance and are therefore specified according to the calculation time step, reference surface type (grass in this case) and, as suggested by Allen et al. (2006), the time of day.

The meteorological data required to evaluate Eq. (2) (using Allen et al., 1998) are: air temperature, relative humidity, wind speed and solar radiation; the detail of the calculations is not repeated here as it is well known (and lengthy and complicated) and can be found in Allen et al. (1998).

\subsection{Spatially distributed estimates of evapotranspiration}

Using the UM forecasts of meteorological variables on the model grid, $\mathrm{ET}_{0}$ values are calculated in hourly time-steps for each grid point, for a subset of the SAWS UM domain. In Fig. 4 a typical map of $\mathrm{ET}_{0}$ calculated at an hourly time step is shown. In this case (12:00 SAST, or 10:00 UTC) a $10 \mathrm{~h}$ ahead forecast of the meteorological variables has been used together with the corresponding LSA-SAF radiation estimate, using FAO56 to solve Eq. (2). A typical linear regression through the origin between the two $\mathrm{ET}_{0}$ estimates is shown in Fig. 6. The regression compares the $\mathrm{ET}_{0}$ computed from observations at each station in the SAWS automatic weather station network (Fig. 1) to the $\mathrm{ET}_{0}$ computed at the nearest UM grid point in the map shown in Fig. 4. Since it is well known that the $R^{2}$ value is reduced for regressions through the origin (Gordon, 1981) and is in fact disputed as a measure of the goodness of fit by some (Eisenhauer, 2003), the Pearson correlation coefficient is also given for comparison. The $R^{2}$ of 0.78 and Pearson correlation coefficient of 0.90 both indicate a strong correspondence between the model forecast and station-based $\mathrm{ET}_{0}$, while the slope of the regression indicates a lack of bias since it is close to one. 
Reference Crop Evapotranspiration - 22/02/2007

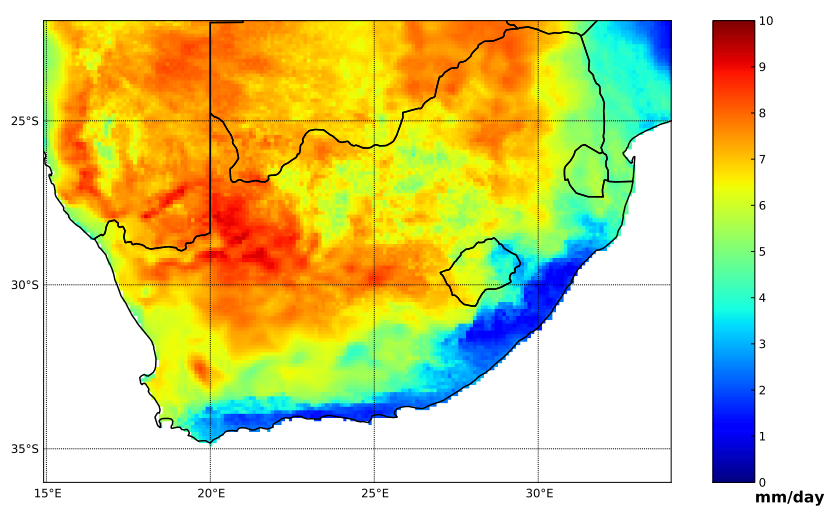

Fig. 5. Daily total of $\mathrm{ET}_{0}$ computed by summing hourly estimates based on NWP forecast data and LSA-SAF radiation estimates, as in Fig. 4.

The strong correlations so obtained between the station and spatially distributed $\mathrm{ET}_{0}$ estimates (at the station locations) indicate that the spatial estimates based on Unified Model forecasts reproduce the $\mathrm{ET}_{0}$ well at many locations throughout South Africa and also help to identify some ground based data which are clearly in error.

\subsection{Obtaining estimates of actual evapotranspiration using TOPKAPI cells}

Having developed a technique to estimate (grass) reference evapotranspiration $\left(\mathrm{ET}_{0}\right)$ using the Penman-Monteith formulation in FAO56, we needed a means of utilizing this information on a day-by-day basis to obtain actual evapotranspiration $\left(\mathrm{ET}_{a}\right)$ in a way that adjusts according to dynamic changes due to vegetation health and water availability for evaporation and transpiration. The TOPKAPI distributed hydrological model was applied in catchment mode using South African data-sets by Vischel et al. (2008a,b), where the local adaptation of the model is described in detail. Each of the cells (in our case $1 \mathrm{~km}$ square, the limit of applicability of the parameters describing the observed physical characteristics of the cell) is modelled as a stack of stores: soil, overland and (where applicable) channel stores. A sketch of the connectivities in the cells appears in Fig. 7. Its application as a surrogate Land Surface Model is described in the following paragraphs, noting that its hydrological background defines drainage from the soil store as lateral, driven by Darcy's equation and the local slope. A point needing emphasis is that, unlike in hydrological applications, in LSM mode the TOPKAPI cell parameters have not been calibrated - they are fixed at their field observation values.

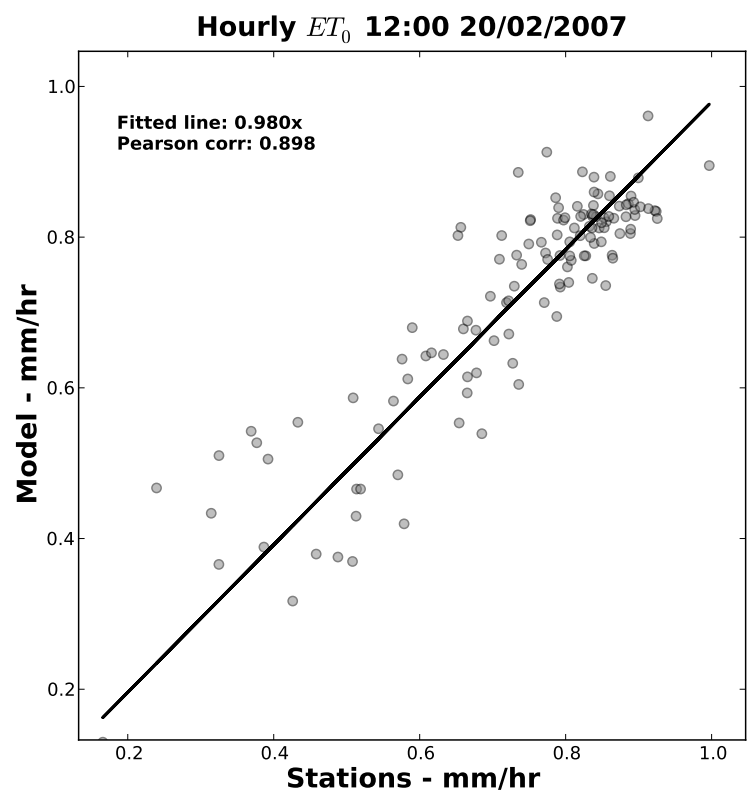

Fig. 6. A typical regression between hourly totals of $\mathrm{ET}_{0}$ computed from forecast model data and observed meteorological parameters at 164 automatic weather stations (Fig. 1).

In our implementation of the TOPKAPI model we chose to use water stress and a crop factor to modify $\mathrm{ET}_{0}$ (e.g. Allen et al., 1998) and model $\mathrm{ET}_{a}$ as shown in Eq. (3)

$\mathrm{ET}_{a}=K_{s} K_{c} \mathrm{ET}_{0}$

where $K_{s}$ is a water stress coefficient between 0 and 1 (we use a direct linear relationship with the degree of saturation in the soil store), and $K_{c}$ is a coefficient dependent on vegetation health and the available water at the soil surface.

Tasumi et al. (2005) suggest that NDVI is a good surrogate for $K_{c}$, as long as the vegetation is fairly well developed and transpiring. We adapted their formulation to allow for evaporation from wet soil when vegetation (hence NDVI) is low. Tasumi et al. (2005) give the derived relationships between $K_{c}$ (which they define as the ratio $\mathrm{ET}_{a} / \mathrm{ET}_{0}$; for irrigated crops i.e. $\left.K_{s}=1\right)$ and NDVI. Their work defines a basal $K_{c b}$ relationship that, if used by itself, produces a progressively smaller $K_{c}$ as NDVI (vegetation cover) reduces. In addition, they show that for very low NDVI, $K_{c}$ can vary from 0 to 1 , which is interpreted to be the evaporation from wet bare soil. The $K_{c b}$ curve behaves as expected for values of NDVI above 0.6 , but below that one needs to allow for direct evaporation from wet soil.

We compute a first estimate of $K_{c}$ using the $K_{c b}$ base-line and adjust this to accommodate a wet bare soil when vegetation is sparse and not actively transpiring. The formulation we adopted was the concept of a virtual store EV which we call the "available water for evapotranspiration". We allow EV to experience carry-over during a rainy period using a simple correlation $R$, modified with a limited amount of 


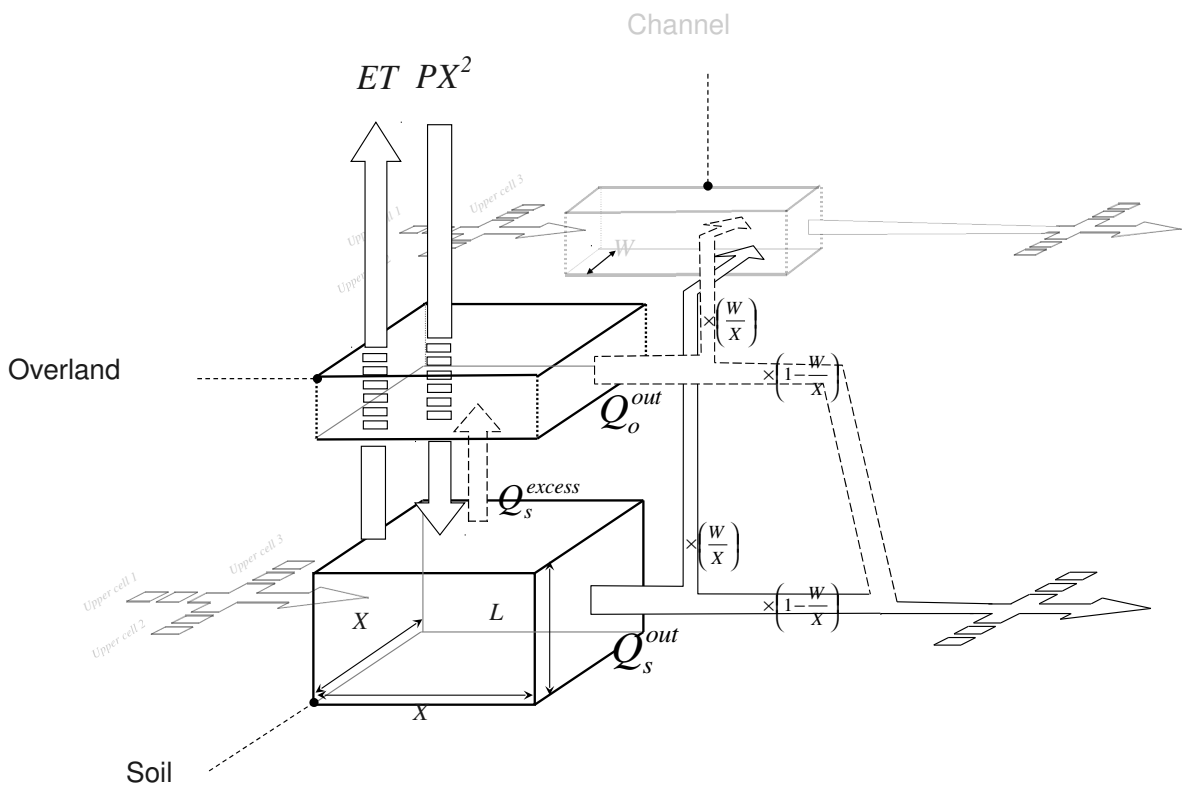

Fig. 7. A schematic representation of a typical TOPKAPI cell and the associated water transfers. Greyed out portions are not used in the pseudo-LSM mode. Adapted from Vischel et al. (2008b).

rainfall (it cannot exceed $\mathrm{ET}_{0}$ ) with up to $\mathrm{ET}_{0}$ being removed on the previous day. The $\mathrm{ET}_{a}$ on the current day cannot exceed the value of $\mathrm{EV}$ nor $K_{c} \mathrm{ET}_{0}$ if there is well developed vegetation. The formulation is as follows, enabling us to calculate $\mathrm{ET}_{a}$ for each $3 \mathrm{~h}$ model time-step:

$$
\begin{aligned}
& \mathrm{EV}_{i}=\min \left(\mathrm{ET}_{0}, \max \left(R * \mathrm{EV}_{i-1}+\min \left(\mathrm{RAIN}_{i}, \mathrm{ET}_{0}\right)-\mathrm{ET}_{0}, 0\right)\right) \\
& \mathrm{ET}_{a}^{i}=K_{s} \max \left(\mathrm{EV}^{i}, K_{c} \mathrm{ET}_{0}\right)
\end{aligned}
$$

where $\operatorname{RAIN}_{i}$ is the rainfall estimate at the current time-step.

In summary, the formula allows evaporation of some of the rainfall up to a maximum of the current $\mathrm{ET}_{0}$ at times when there is no vegetation and also allows removal of soil water by active vegetation as soon as NDVI dominates.

\section{Soil moisture modelling using TOPKAPI cells}

The TOPKAPI model code has been adapted to allow it to be operated as a collection of cells that are independent of their neighbours. Each model cell has a plan area of $1 \times 1 \mathrm{~km}$ and the 6984 cell centres are located on a regular latitude and longitude grid with a grid spacing of $0.125^{\circ}$. The model parameters (soil properties, slopes, land-use characteristics) have been determined for each cell, based on several static datasets and primarily using the methods described in Vischel et al. (2008a) and were not post-calibrated at all. The rainfall forcing applied is the real-time TRMM 3B42RT product (Huffman et al., 2007), which is automatically downloaded from the NASA server and processed locally. The $\mathrm{ET}_{a}$ forcing is based on a modification of the FAO56 (Allen et al., 1998) reference crop evapotranspiration $\left(\mathrm{ET}_{0}\right)$, accounting for vegetation state and the availability of both surface and soil water to meet the evaporative demand (as described in Sect. 2.4). The technique we developed to estimate $\mathrm{ET}_{a}$ from $\mathrm{ET}_{0}$, NDVI and rainfall, turns out to be very similar to the methodology developed by Guerschman et al. (2009). A flow-chart showing the computational procedure is offered in Fig. 8. The data-sets applicable at TOPKAPI cell scale shown in the figure are are the static ones: local slope (obtained from $90 \mathrm{~m}$ DEM), surface roughness (obtained from land cover classes), soil depth, soil conductivity and slowly varying NDVI.

The TOPKAPI simulations are run once daily with a $3 \mathrm{~h}$ time step and the results archived. The purpose of the computation is to obtain the Soil Saturation Index (SSI) given in Eq. (5). SSI is defined as the percentage of soil void space taken up by water

$\mathrm{SSI}=100\left(\frac{\theta-\theta_{r}}{\theta_{s}-\theta_{r}}\right)$

where $\theta$ is the soil moisture content, $\theta_{s}$ is the saturated moisture content and $\theta_{r}$ is the residual moisture content. Figure 9 shows a snapshot of the computed SSI state for 00:00 UTC 18 December 2008. The colour scale ranging from brown to blue indicates the Soil Saturation Index (SSI) as a percentage, with light grey indicating regions where no modelling was carried out.

\section{Inter-comparison of TOPKAPI and ASCAT}

In the absence of in situ soil water data available routinely in enough detail, inter-comparisons between the TOPKAPI modelled SSI and a remote sensing soil moisture retrieval 


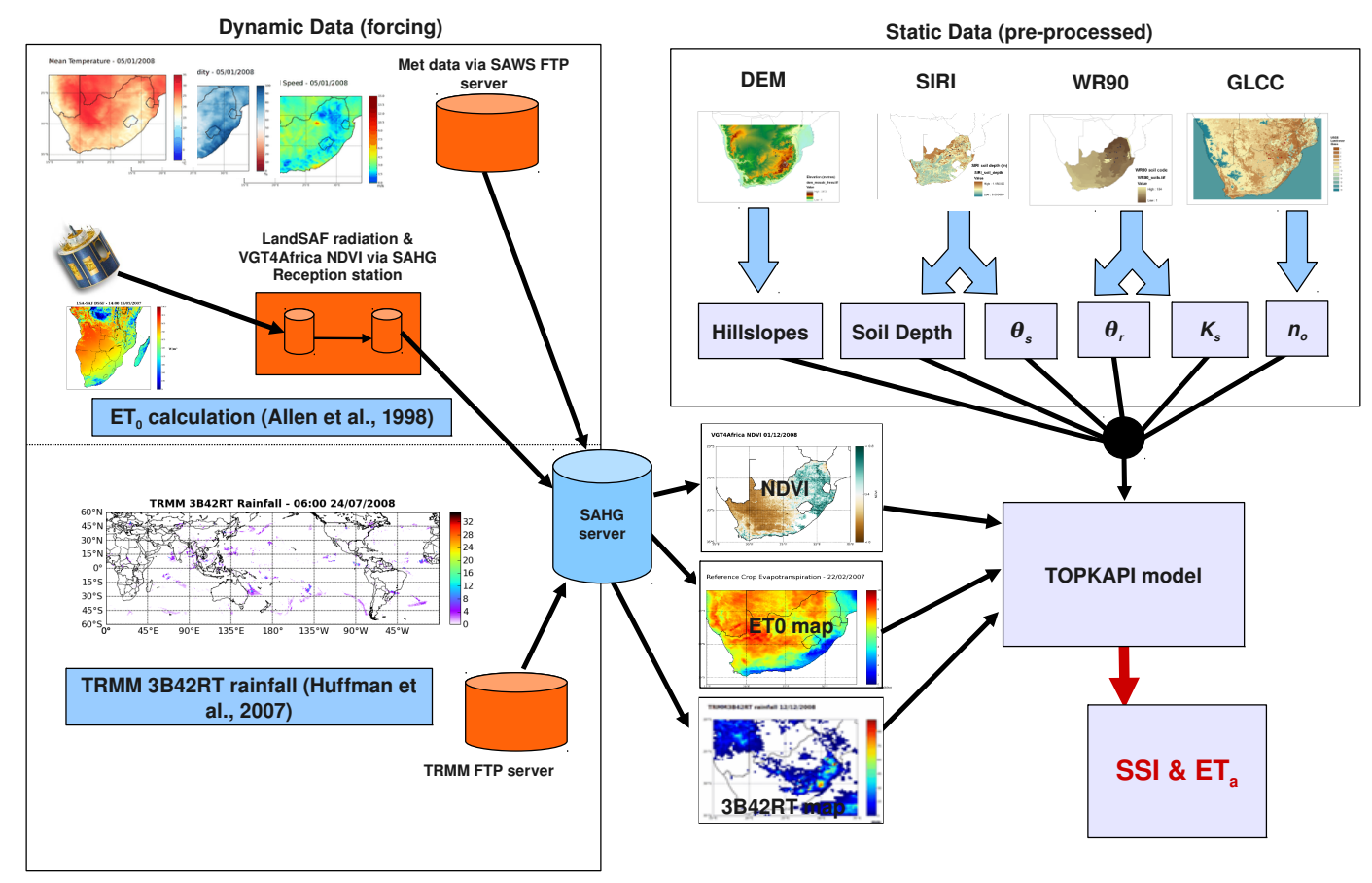

Fig. 8. A flow chart, showing the sources of data used to compute SSI with the TOPKAPI model. The dynamic forcing data comprises rainfall (bottom left panel) and the data required to compute $\mathrm{ET}_{0}$ (top left panel). The static data are used to derive local slope (DEM) and soil properties. The overland roughness $n_{o}$ and soil condictivity $K_{S}$ control the flow of water in the cell, while the the residual and saturated soil moisture contents $\left(\theta_{r}, \theta_{s}\right)$ are combined with the soil depth to compute available water storage capacity.

have been carried out. This section describes the remote sensing based soil moisture product, the method used in the comparisons, and presents selected results and discussion.

\subsection{ASCAT surface soil moisture}

The advanced scatterometer (ASCAT) instrument on-board the polar orbiting METOP satellite is an active microwave instrument that measures backscatter from terrestrial surfaces. The backscatter signal measured by ASCAT is strongly influenced by the water content of soil, since the soil dielectric constant increases with increasing water content (Wagner et al., 2007). In this study we considered the $25 \mathrm{~km}$ ASCAT soil moisture product, which is available on a $12.5 \mathrm{~km}$ grid defined by the METOP orbit geometry. We were able to acquire only 5 months (1 August to 31 December 2008) of ASCAT data covering the region from the EUMETSAT UMARF archive.

The ASCAT retrieval is a change detection method, with the current backscatter measurement being scaled between wet and dry backscatter limits for each location in order to produce a relative soil moisture value (Bartalis et al., 2008). This surface soil moisture (SSM) value can be interpreted in terms of soil moisture content if the soil properties (saturated and residual moisture contents) are known for the location. In this study we have only considered the SSM since it is most similar to the TOPKAPI SSI that we compute. This premise is, based on the assumption made by Bartalis et al.

\section{Regional modelled soil wetness 18/12/2008}

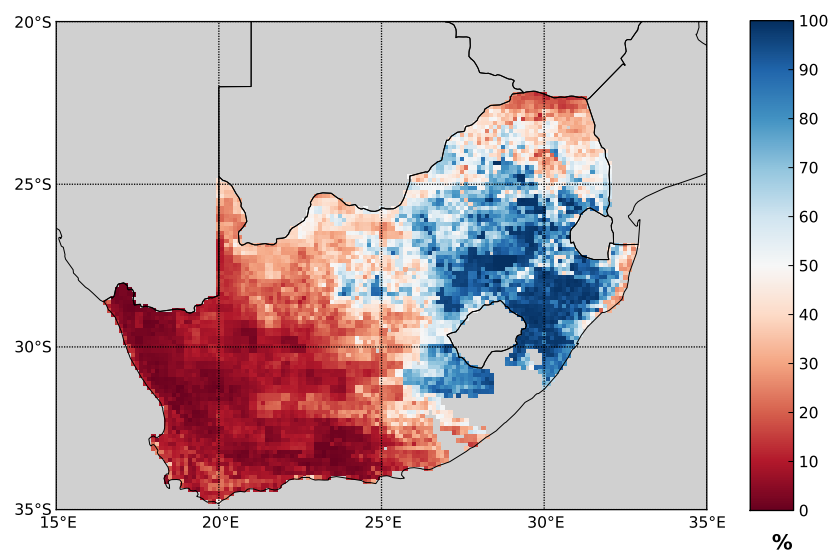

Fig. 9. An example of the country-wide soil moisture estimates produced by TOPKAPI in LSM mode. The colour scale represents the Soil Saturation Index (SSI), the percentage of soil void space filled by water (see Eq. 5). The grey gaps are due to a current lack of suitable soil property data.

(2008), that the wet and dry backscatter limits have been computed from a time series that contains at least one observation where the soil was at its saturated moisture content (as well as at least one observation where the soil was at its residual moisture content). 
ASCAT relative surface soil moisture

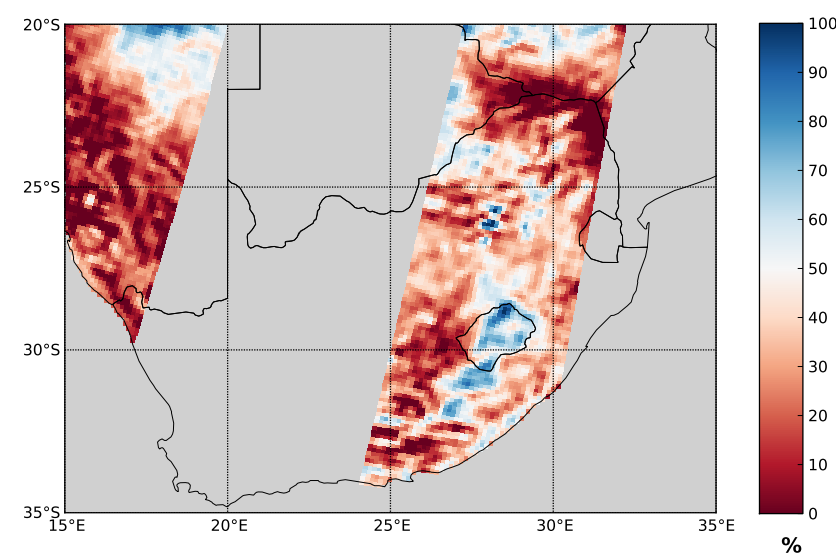

Fig. 10. Relative surface soil moisture (SSM) retrieval from ASCAT. The satellite overpass time is approximately eight hours after the TOPKAPI SSI estimates shown in Fig. 9.

Figure 10 shows the SSM from a typical METOP overpass. The overpass is eight hours later than the TOPKAPI SSI estimates shown in Fig. 9. The SSM values are clearly lower than the SSI values in general and although there are similar spatial patterns evident, these are not easily discernible without normalizing the values. The the raw ASCAT SSM estimates and the TOPKAPI SSI estimates are not strictly comparable. The first is an estimate of the surface SM, while the latter is an average SM content in the soil profile. The SSM needs to be temporally filtered to a Soil Wetness Index (SWI) before meaningful comparisons can be made. It is only after low pass filtering of the SSM signal in time that stronger correspondence between the two estimates emerges (see Sects. 4.2-4.4).

\subsection{Method of comparison}

Due to the different spatial and temporal sampling of the ASCAT and TOPKAPI based soil moisture estimates, it was difficult to make any objective comparisons without first resampling one or both of the data sets onto common areas and matching the sampling times as closely as possible. In order to begin developing a detailed understanding of the properties of the two estimates, we chose the following approach. First, we selected four different regions of South Africa following the work of Pfeffer (2008). The site selection was largely based on differences in vegetation type and Mean Annual Precipitation (MAP). Figure 11 shows the locations labelled A through D (named Western Cape, Eastern Cape, Liebenbergsvlei and Crocodile respectively), identified on a representation of MAP derived from the WR90 data-set (Midgley et al., 1994).

Soil moisture estimates from TOPKAPI and ASCAT were aggregated over $0.25^{\circ}$ and $0.5^{\circ}$ blocks (at locations A-D) for each of the four climatic regions during the 5 month

\section{Mean Annual Precipitation from WR90 data}

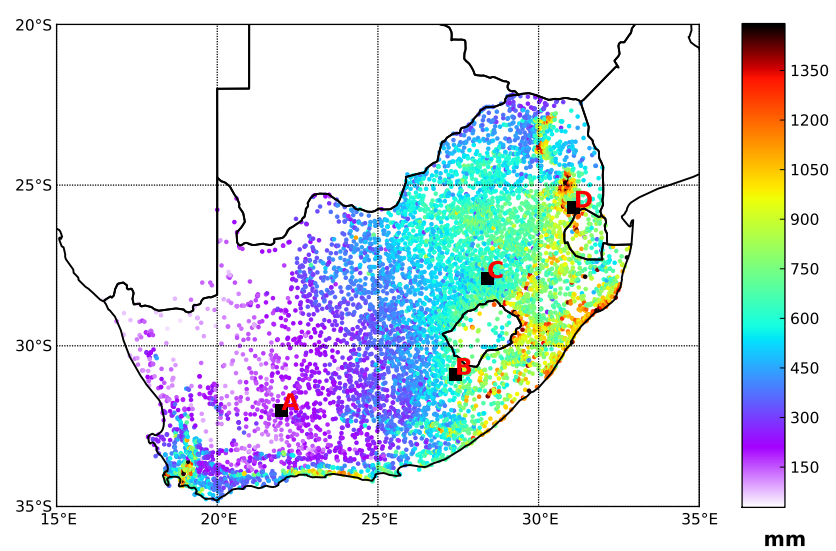

Fig. 11. Locality of the four different areas considered, plotted over Mean Annual Precipitation (MAP) data obtained from WR90 (Midgley et al., 1994). The general trend is for MAP to increase from West to East. An important exception is the southern coastline, which receives significant winter rainfall associated with frontal systems.

period from August to December 2008. The data are plotted in Figs. 12-15 (discussed in the next section), no attempt was made to resample temporally, because the SSI values are computed at 3-h intervals, and are typically close to the METOP overpass times.

Since the ASCAT retrieval is only sensitive to surface soil moisture changes $(<5 \mathrm{~cm}$ depth), the SSM values change rapidly and appear quite noisy. Following the work of Wagner et al. (1999), we chose to apply an exponentially weighted temporal filter, in the form of a discretely equivalent difference equation, to extract the low frequency signal from the spatial mean of the ASCAT retrievals in each block. The expectation was that this would be more representative of the soil moisture state in deeper soil layers, due to smoothing of the near surface signal by infiltration processes. The SSI computed from TOPKAPI is a representative average condition of the entire soil horizon, which varies in depth by location between $400 \mathrm{~mm}$ and $1200 \mathrm{~mm}$.

The initial value of the filter was chosen to be the first available block mean ASCAT soil wetness and the filter's time constant was set at 20 days (Wagner et al., 1999). The filter used is described as

$y_{t}=(1-\alpha) y_{t-1}+\alpha x_{t} ; \quad \alpha=\Delta t / k$

where $y_{t}$ is the current filtered value of the time series, $y_{t-1}$ is the previous filtered value, $x_{t}$ is the current value of soil wetness, $\Delta t$ is the time-step (variable, typically $2-3$ days) between estimates and $k=20$ days is the time constant of the filter. This lag-one autoregressive (AR(1)) difference equation is a discretely coincident analogue of the exponential filter with the same time constant, as shown by Pegram (1980) 


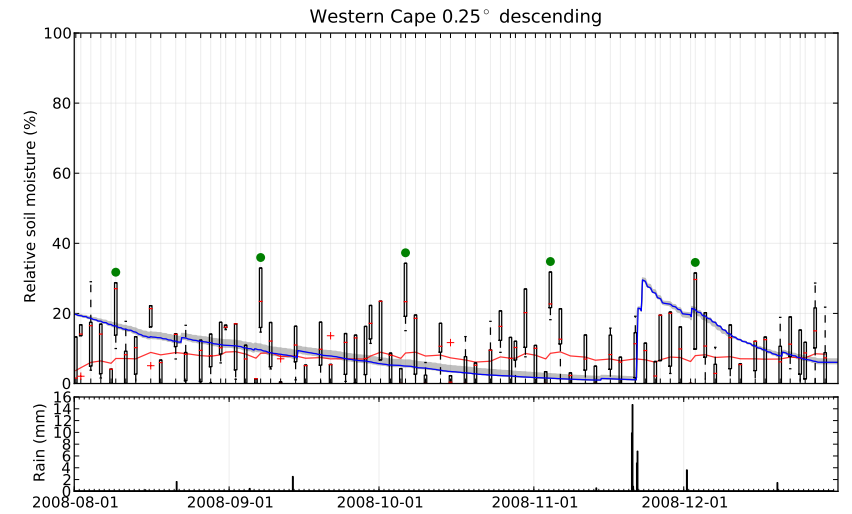

Fig. 12. Site A - Western Cape. TOPKAPI and ASCAT derived soil wetness, and TRMM 3B42RT $3 \mathrm{~h}$ accumulated rainfall. The top panel shows the median TOPKAPI SSI averaged over a $0.25^{\circ}$ block (blue line), with the inter-quartile range of these four estimates within the block shown by the grey fill. The range of ASCAT estimates (they number between 2 and 6 on a given day in a $0.25^{\circ}$ square) within the box at each overpass time is shown by the box and whisker plots (for ascending and descending orbits), while the red line shows the filtered time series of the mean ASCAT estimates. The bottom panel shows a histogram of $3 \mathrm{~h}$ rainfall accumulations. The sequence of green dots highlight a marked increase in the ASCAT estimated soil moisture, which has a periodicity that matches the 29 day repeat cycle of METOP (Figa-Saldaña et al., 2002). It is clear that the ASCAT SSM does not respond to the rainfall in November and is very noisy at this site.

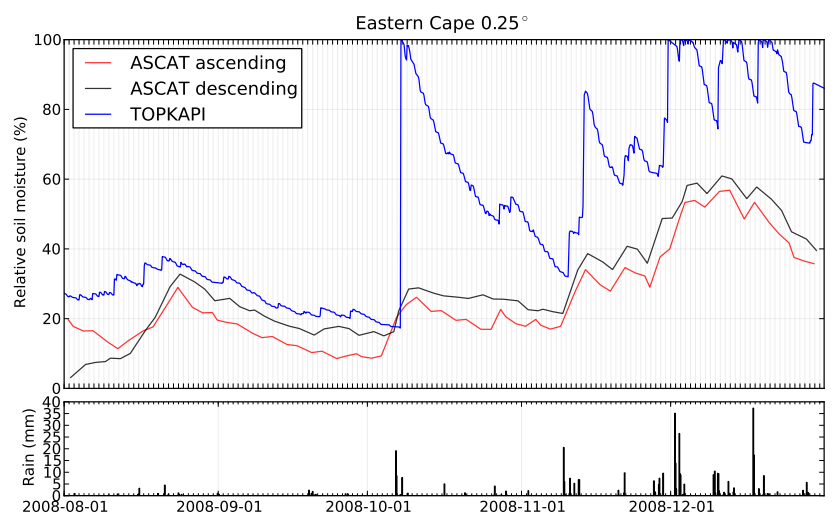

Fig. 13. Site B - Eastern Cape. TOPKAPI and ASCAT derived soil wetness, and TRMM 3B42RT $3 \mathrm{~h}$ accumulated rainfall. The top panel shows the median TOPKAPI SSI averaged over a $0.25^{\circ}$ block as a blue line. The ASCAT SWI estimates within the box are shown in red/black for the ascending and descending orbits. There is no clear way to choose between the ASCAT ascending and descending passes based on their response to rainfall events. The bottom panel shows a histogram of $3 \mathrm{~h}$ rainfall accumulations.

and Diskin and Pegram (1987). We use the approximation: $1-\alpha \approx \exp (-\alpha)$, which is good when $\alpha<0.15$. In this case alpha $=0.05$, so the difference is $0.12 \%$, which is not a problem as the time constant is not that precisely defined. Both the raw and filtered ASCAT estimates for each block

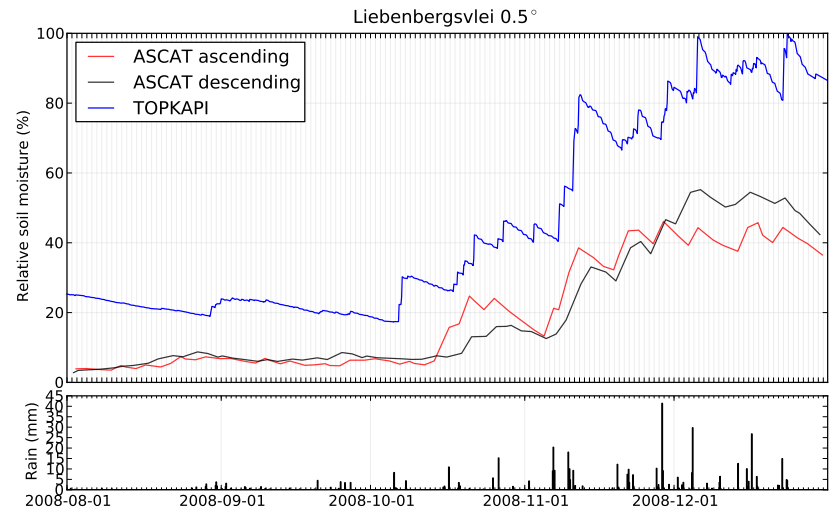

Fig. 14. Site $\mathrm{C}$ - Liebenbergsvlei. The description of this figure is the same as Fig. 13, except that a $0.5^{\circ}$ block has been used.

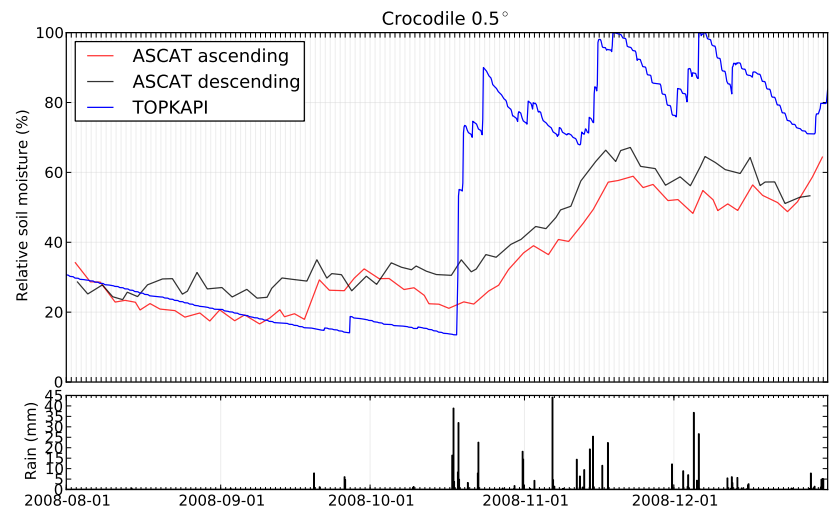

Fig. 15. Site D - Crocodile. The description of this figure is the same as Fig. 13, except that a $0.5^{\circ}$ block has been used.

size were then compared to the equivalent closest (in time) TOPKAPI SSI by means of linear regressions, with the $R^{2}$ of the regression used as a criterion to determine the "goodness of fit". This set of comparisons is presented in Sect. 4.3 below.

\subsection{Results of comparison}

In this section, selected illustrative results of the comparison are presented. We chose to present results at the four sites A to D in different ways to judge the effect of the treatments: averaged over different sized blocks and varying the choice of direction of METOP passes, either descending, ascending or combined. The first set of figures (Fig. 12 through 15) show the time series of soil moisture estimated in each of the four different climatic regions over either $0.25^{\circ}$ or $0.5^{\circ}$ blocks during the 5 month analysis period running from 1 August 2008 to 31 December 2008. The top panel in Fig. 12, for the Western Cape site (A) shows the block median TOPKAPI SSI estimate as a blue line, with the interquartile range indicated by the grey shaded region. The box and whisker plots show the range of ASCAT SSM estimates 

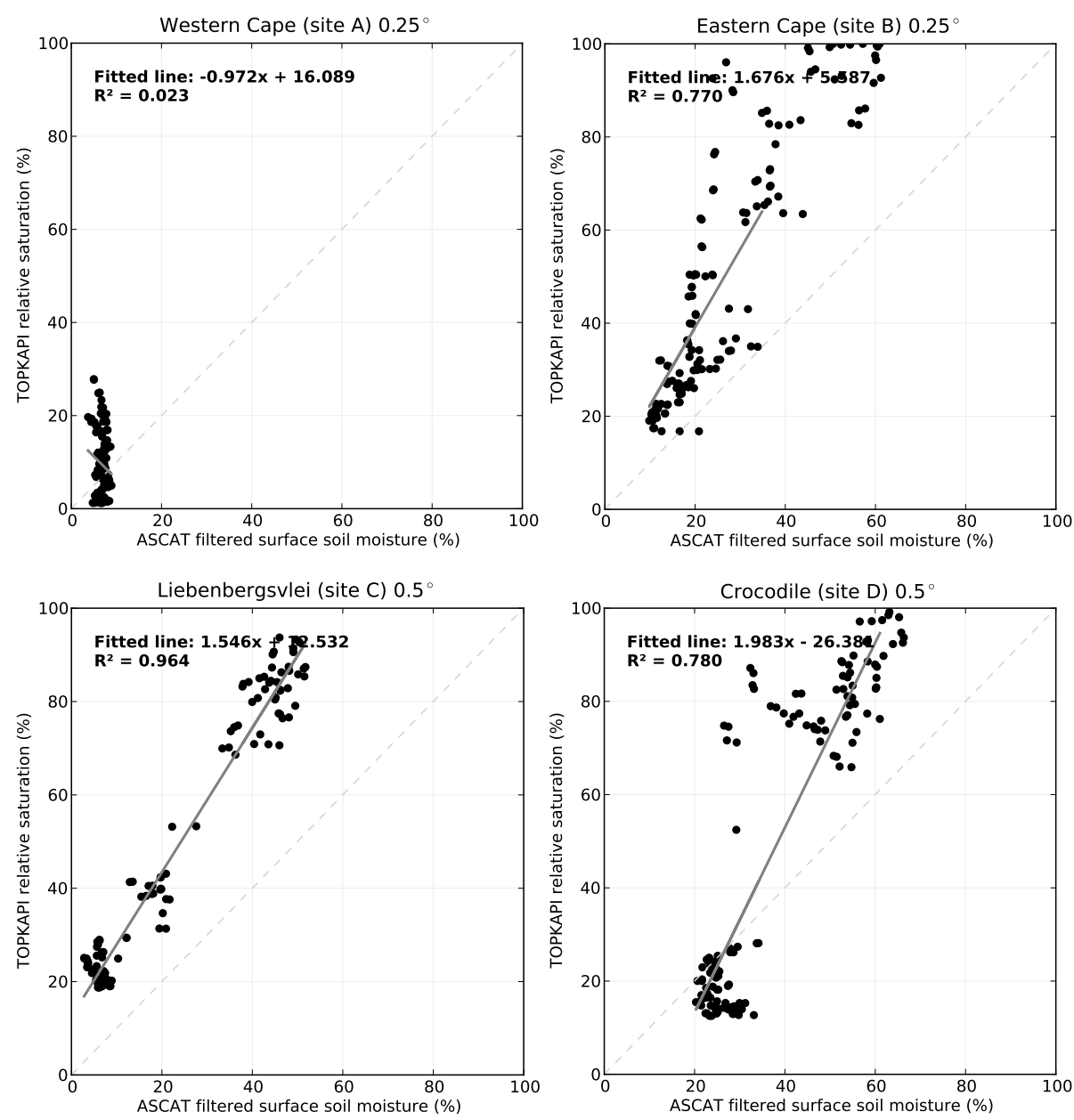

Fig. 16. Scatter plots of the block mean ASCAT soil moisture and closest (in time) block mean TOPKAPI SSI, showing the fitted linear regression line and $R^{2}$ values. The points in these 4 images correspond to the comparison of TOPKAPI SSI estimates with ASCAT SWI values shown in Figs. 12-15.

within each block. The red line shows the filtered block mean values to produce the ASCAT SWI estimates, using $T=20$ days in Eq. 6. The bottom panel shows $3 \mathrm{~h}$ rainfall accumulations estimated by TRMM 3B42RT. There is a clear 29 day periodicity evident in the ASCAT data shown in Fig. 12, for the Western Cape site. This period matches the 29 day repeat cycle of METOP (Figa-Saldaña et al., 2002) and may be a result of the ASCAT incidence angle interacting with topography (e.g. Bartalis et al., 2006).

Figures 13-15 show similar plots for the remaining 3 sites, with the blue line in the top panel showing the spatial mean TOPKAPI estimate and the red/black lines showing the spatial mean of SWI for ascending/descending ASCAT overpasses.

It turns out that, after exponential filtering the ASCAT data with the simple AR(1) model (Eq. 6), the relationship for 3 of the sites is nearly linear and highly correlated. Figure 16 shows scatter plots of the block mean TOPKAPI soil moisture against the block mean filtered ASCAT SWI series.
Figure 17 shows a map of the coefficient of determination $\left(R^{2}\right)$ for the linear regression computed between block averaged SSI and SWI on $0.25^{\circ}$ blocks covering the region.

\subsection{Discussion of results}

As shown by the box and whisker plots in Fig. 12, the ASCAT SSM shows a high variability both within each block and in time (the same behaviour is evident at the other sites as well). This is expected since the near surface $(0-50 \mathrm{~mm})$ soil moisture will either evaporate or infiltrate into deeper soil layers within a fairly short space of time. The ASCAT SWI values do increase in response to most rainfall events. For example there are clear increases due to rainfall in midAugust and early October shown in Fig. 13.

The ASCAT SWI values show a strong link with the TOPKAPI SSI estimates for three of the locations: (B) Eastern Cape, (C) Liebenbergsvlei and (D) Crocodile. The exception is the (A) Western Cape's behaviour displayed in Fig. 12, 
Filtered ASCAT and TOPKAPI regression

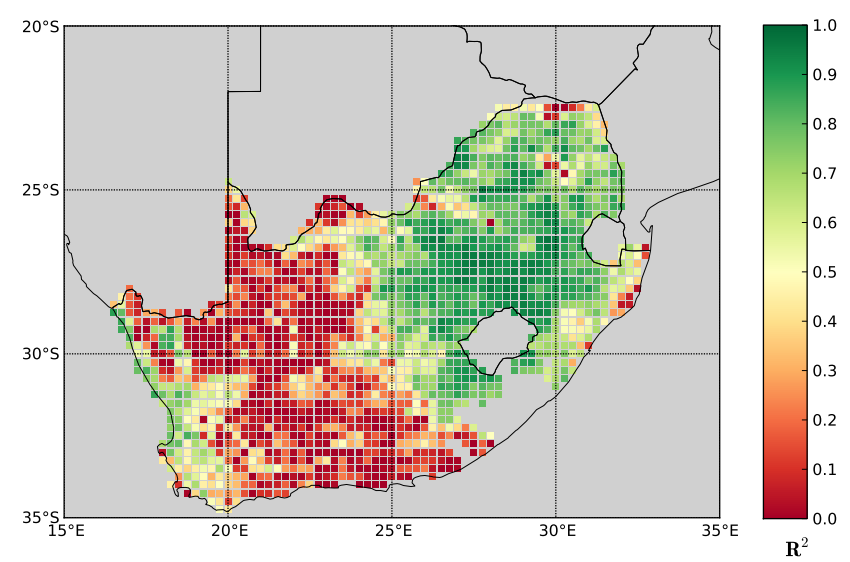

Fig. 17. Maps of $R^{2}$ computed for the block mean $\left(0.25^{\circ}\right)$ filtered ASCAT soil moisture as SWI and closest (in time) block mean TOPKAPI SSI. These values were obtained from calculations like those in Fig. 16.

where the 29 day periodicity in the ASCAT SSM estimates is highlighted by green dots (location A in Fig. 11). This correspondence is shown both in terms of the general trend and in the response to individual rainfall events when examining Figs. 12-15 and the regressions in Fig. 16. There are some notable exceptions to the strong linear relationship between SWI and SSI, which we can not yet explain. The first exception is found in mid-October, where the ASCAT SWI response after the rainfall event in Fig. 15 (Crocodile catchment) is lower than expected given the large rainfall input. Another exception is that the SWI estimates are climbing during August on the Liebenbergsvlei (Fig. 14), when there appears to be no rain. In this case we can offer some possible explanations i) the TRMM rainfall product may have failed to detect rainfall that occurred during that period ii) the soil moisture may have been increasing due to the effects of irrigation (or groundwater), which are not captured by the TOPKAPI modelling process.

Figure 17 shows that the TOPKAPI SSI and ASCAT SWI estimates are generally well correlated in the more densely populated and wetter eastern regions of South Africa, while the arid central western regions (which are understandably sparsely populated) show poor correspondence. In places where the correspondence is good (high $R^{2}$ ) it seems reasonable to suggest that both modelled and remote sensing estimates are correctly responding to the true soil moisture dynamics. In the regions of poor correspondence (low $R^{2}$ ), it is unclear which (if any) of the estimates is producing credible information on the changes in soil moisture conditions. Additional information is required to resolve this problem, in the form of in situ measurements and alternative independent estimates for further corroboration.

\section{ASCAT relative surface soil moisture errors}

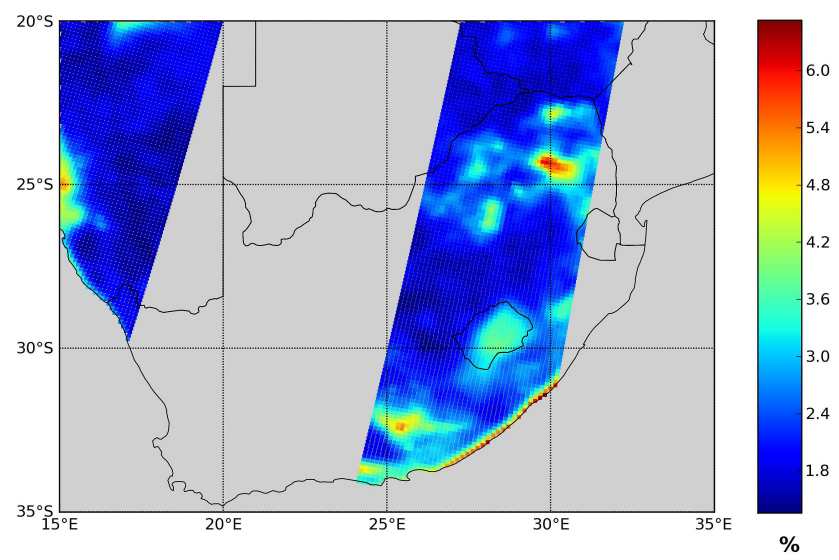

Fig. 18. Estimated error (distributed with the data by EUMETSAT) of the relative surface soil moisture retrieval from ASCAT. The satellite overpass matches that shown in Fig. 10.

\section{Error structures}

Some assessment of the errors in the meteorological variables used to compute evapotranspiration was given in Sect. 2. When it comes to the other parameters used in the TOPKAPI cell calculations, we have taken the estimates at face value. We have some feeling for the errors in the TRMM 3B42 RT rainfall estimates based on the work of others (Huffman et al., 2007; Villarini et al., 2009), but at this juncture have not performed our own evaluation in this preliminary study. However, we are committed to so do in the 3-year follow-on study commencing in April 2010. It is the purpose of this section to attempt to assess the usefulness of the TOPKAPI SSI estimates, by evaluating the perceived error structures of the ASCAT SWI estimates with which it compares relatively favourably over a large part of South Africa, but not so well on the remainder (as shown in Fig. 17).

The high variability and the 29 day repeat cycle of the ASCAT raw SSM observations prompted us to look more closely at the data. The SSM estimates from ASCAT for a given overpass are collected in two swaths, one East the other West of the METOP path (Naeimi et al., 2009). Figure 10 shows the estimate for the downward pass on $18 \mathrm{De}$ cember 2008. In addition to the soil moisture estimates, the data-set includes an error estimate for each location in units of SSM \%, as shown in Fig. 18. This error estimate, due to instrument noise, speckle and azimuthal effects, is calculated by EUMETSAT from the standard deviation of the backscatter difference between the fore and aft antennas and propagated through the calculation procedure to give an error estimate in SSM \% (Bartalis et al., 2008). Understandably, there are larger errors at the coast and over the mountainous and forested areas of the Southeast (Cape) and the Northeast 
ASCAT mid-antenna incidence angles

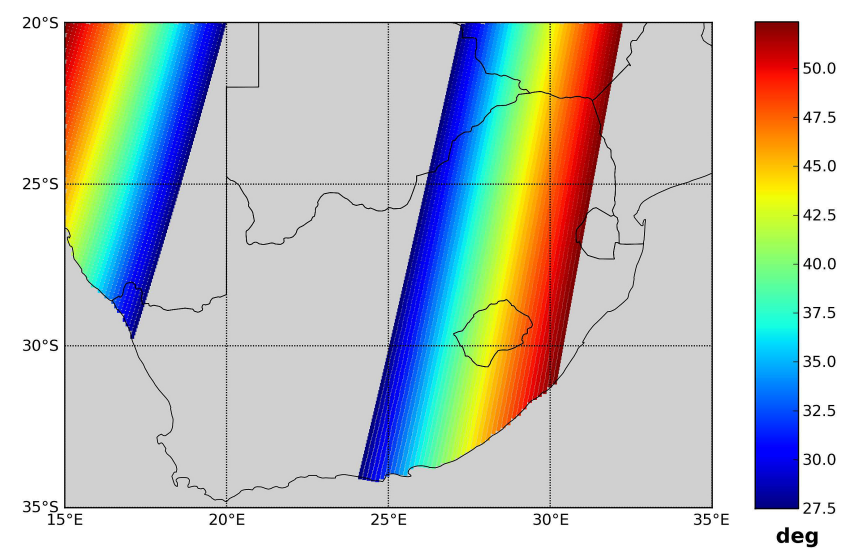

Fig. 19. Incidence angle (in decimal degrees) for the middle antenna of the ASCAT instrument. The satellite overpass time matches that shown in Fig. 10.

(Mpumalanga). Surprisingly, given the behaviour of the boxplots in Fig. 12, the error structure shown in Fig. 18 does not appear to depend on the incidence angle of the C-band, shown in Fig. 19 for the middle antenna; note that the incidence angle varies from 25 to $53^{\circ}$ across each path of the swath.

Following on from the analysis displayed in Fig. 17 we collected all the absolute ASCAT SSM errors computed by EUMETSAT in each $0.25^{\circ}$ square over the 5 months of our study period. These were averaged over each block and averaged over time. The results appear in Fig. 20, where the effect of the eastern coastline and the associated coastal forest will be seen in green. Most of the remainder of the country averages out at a remarkably small 1 to $2 \%$, with the exception of the known mountainous regions.

Figure 20 contrasts starkly with Fig. 21, which appears in Bartalis et al. (2008) and is based on ERS data. Figure 21 shows global SSM absolute errors scaled (normalized) by the observed range of SSM estimates at each location. A closer scrutiny over the southern African region of Fig. 21 indicates substantial normalized errors (5 to 7\%) in the Western half of South Africa and smaller (2 to 3\%) errors over the Eastern half. This pattern agrees broadly with the map of correlations between SSM and SSI estimates that we display in Fig. 17. It is clear that these differences match very well with the mean annual precipitation shown in Fig. 11, which we suggest might be a good indicator of the range of Soil Wetness errors in specific locations. The implication is that ASCAT is likely to be good in wet areas but not so good in dry areas, because there the signal to noise ratio is relatively small. Because the scatterometer instruments onboard ERS and METOP are expected to provide similar estimates of SSM (Bartalis et al., 2008), we suggest that the error of the ASCAT SSM relative to the observed range in arid regions may provide an explanation for the observed low correlations

\section{ASCAT SM error}

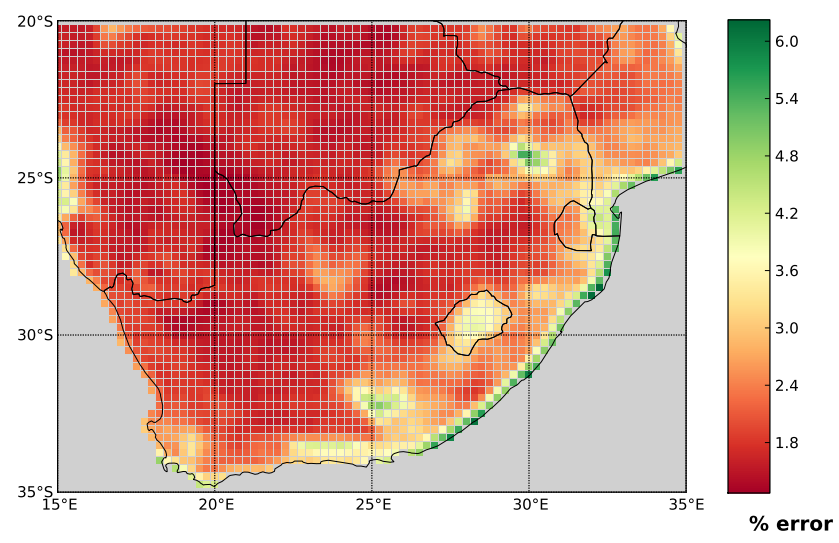

Fig. 20. Averages of five months of the SSM absolute error estimates provided with the ASCAT product by EUMETSAT. The reported error estimates have been averaged over $0.25^{\circ}$ blocks for each overpass and the time average for each block calculated.

between SSI and SWI in dry areas shown in Fig. 17. In summary, the results of the comparisons are very encouraging over half of South Africa. However, despite the above conjecture, we have not yet been able to conclusively determine the cause of the discrepancies in the arid areas.

\section{Conclusions}

In this paper we have introduced an automated approach to modelling soil moisture state in detail over South Africa using the TOPKAPI hydrological model in LSM mode forced by rainfall and evapotranspiration estimates. This system is currently running automatically on an ongoing basis, with results on our website (http://sahg.ukzn.ac.za/).

We have compared the SSI simulations produced by TOPKAPI to surface soil moisture retrievals from the ASCAT instrument on-board the METOP polar orbiting satellite. The ASCAT soil moisture product is operationally disseminated for the European region, and will soon be operationally available in Africa. We found a good correspondence between time filtered values of SSM averaged over $0.25^{\circ}$ and $0.5^{\circ}$ blocks for several climatic regions in South Africa, but found poor correspondence in the dry Western Cape site considered. The $R^{2}$ maps in Fig. 17 show that this is to be expected since the Western Cape site falls in the broad region of poor correspondence between the TOPKAPI and ASCAT estimates. These results are consistent with those found by Vischel et al. (2008b) for the Liebenbergsvlei catchment. In that earlier desk-top study we compared the soil moisture estimates obtained from a detailed catchment implementation of TOPKAPI (a network of laterally inter-connected cells) with the time filtered soil moisture product retrieved from ASCAT's predecessor on-board the ERS-1 and ERS-2 polar orbiters. 


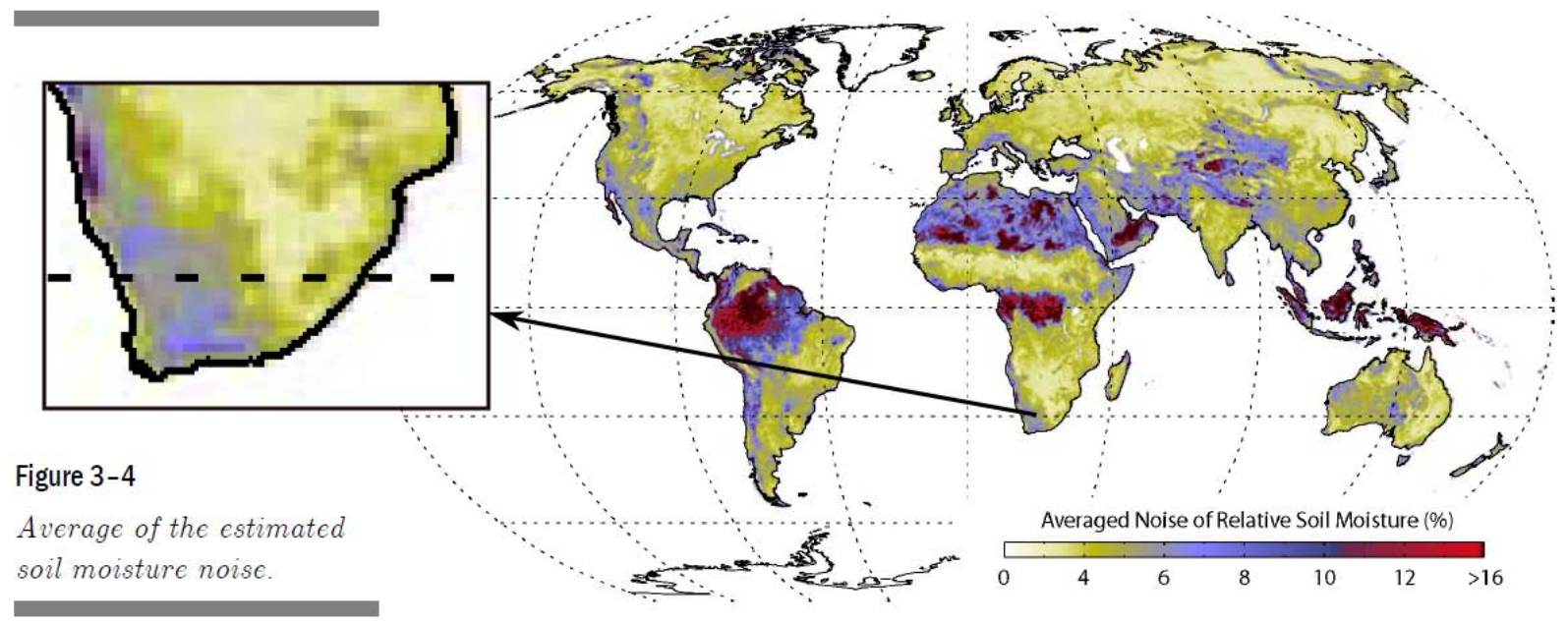

Fig. 21. Yearly average of ERS based surface soil moisture retrieval errors scaled by range. This figure is adapted from Bartalis et al. (2008). The broad patterns shown over South Africa, which are effectively a measure of the signal to noise ratio, match those shown in Fig. 17, which shows the correlation computed between ASCAT SSM and TOPKAPI SSI.

These results are encouraging as they suggest that there is a good possibility of improving the space time coverage of soil moisture as estimated by active microwave sensors onboard polar orbiting satellites, by using hydrological modelling (in LSM mode or in detail where required) and assimilating the information provided by microwave sensors (e.g. Crow and Ryu, 2009; Parajka et al., 2006). The resulting soil moisture field will be valuable for Flash Flood Guidance and other applications in the region.

Acknowledgements. The authors gratefully acknowledge the support of the South African Water Research Commission, which provided funding for this work under contract K5/1683. In addition, we are indebted to SAWS for routinely providing us with their UM outputs in real time and for partnering with us in the EC contract 8-ACP-ROR-016: Research for the Utilisation of MSG in Southern Africa (RUMSA) by means of which we freely obtain our EUMETSAT data.

Edited by: N. Verhoest

\section{References}

Albergel, C., Rüdiger, C., Carrer, D., Calvet, J.-C., Fritz, N., Naeimi, V., Bartalis, Z., and Hasenauer, S.: An evaluation of ASCAT surface soil moisture products with in-situ observations in Southwestern France, Hydrol. Earth Syst. Sci., 13, 115-124, 2009 , http://www.hydrol-earth-syst-sci.net/13/115/2009/.

Allen, R., Pereira, L., Raes, D., and Smith, M.: Crop evapotranspiration - Guidelines for computing crop water requirements, FAO Irrigation and drainage paper, Rome, Tech. rep., 56, 1998.
Allen, R., Pruitt, W., Wright, J., Howell, T., Ventura, F., Snyder, R., Itenfisu, D., Steduto, P., Berengena, J., Yrisarry, J., Smith, M., Pereira, L., Raes, D., Perrier, A., Alves, I., Walter, I., and Elliott, R.: A recommendation on standardized surface resistance for hourly calculation of reference $E T_{0}$ by the FAO56 PenmanMonteith method, Agr. Water Manage., 81, 1-22, 2006.

Bartalis, Z., Scipal, K., and Wagner, W.: Azimuthal anisotropy of scatterometer measurements over land, IEEE T. Geosci. Remote, 44(8), 2083-2092, 2006.

Bartalis, Z., Naeimi, V., Hasenauer, S., and Wagner, W.: ASCAT Soil Moisture Product Handbook, ASCAT Soil Moisture Report Series, Tech. Rep. 15, Institute of Photogrammetry and Remote Sensing, Vienna University of Technology, Austria, 2008.

Crow, W.: A Novel Method for Quantifying Value in Spaceborne Soil Moisture Retrievals, J. Hydrometeorol., 8, 56-67, 2007.

Crow, W. T. and Ryu, D.: A new data assimilation approach for improving runoff prediction using remotely-sensed soil moisture retrievals, Hydrol. Earth Syst. Sci., 13, 1-16, 2009, http://www.hydrol-earth-syst-sci.net/13/1/2009/.

Diskin, M. H. and Pegram, G. G. S.: A study of cell models: 3. A pilot study on the calibration of manifold cell models in the time domain and in the Laplace domain, Water Resour. Res., 23(4), 663-673, 1987.

Eisenhauer, J.: Regression through the origin, Teaching Statistics, 25, 76-80, 2003.

Figa-Saldaña, J., Wilson, J., Attema, E., Gelsthorpe, R., Drinkwater, M., and Stoffelen, A.: The advanced scatterometer (ASCAT) on the meteorological operational (MetOp) platform: A follow on for European wind scatterometers, Can. J. Remote Sens., 28, 404-412, 2002.

Gordon, H.: Errors in computer packages. Least squares regression through the origin, The Statistician, 30, 23-29, 1981. 
Guerschman, J., Dijk, A. V., Mattersdorf, G., Beringer, J., Hutley, L., Leuning, R., Pipunic, R., and Sherman, B.: Scaling of potential evapotranspiration with MODIS data reproduces flux observations and catchment water balance observations across Australia, J. Hydrol., 369, 107-119, 2009.

Huffman, G., Adler, R., Bolvin, D., Gu, G., Nelkin, E., Bowman, K., Hong, Y., Stocker, E., and Wolff, D.: The TRMM Multi-satellite Precipitation Analysis: Quasi-global, multi-year, combined-sensor precipitation estimates at fine scale, J. Hydrometeorol., 8, 38-55, 2007.

Kerr, Y., Waldteufel, P., Wigneron, J.-P., Martinuzzi, J.-M., Font, J., and Berger, M.: Soil moisture retrieval from space: The soil moisture and ocean salinity mission (SMOS), IEEE T. Geosci. Remote, 39, 1729-1735, 2001.

Liu, Z. and Todini, E.: Towards a comprehensive physically-based rainfall-runoff model, Hydrol. Earth Syst. Sci., 6, 859-881, 2002, http://www.hydrol-earth-syst-sci.net/6/859/2002/.

McCabe, M. and Wood, E.: Scale influences on the remote estimation of evapotranspiration using multiple satellite sensors, Remote Sens. Environ., 105, 271-285, 2006.

Midgley, D., Pitman, W., and Middleton, B.: Surface Water Resources of South Africa 1990, Water Research Commission Report, Tech. rep. No. 298/94, 1994.

Naeimi, V., Bartalis, Z., and Wagner, W.: ASCAT Soil Moisture: An Assessment of the Data Quality and Consistency with the ERS Scatterometer Heritage, J. Hydrometeorol., 10, 555-563, 2009.

Njoku, E., Jackson, T., Lakshmi, V., Chan, T., and Nghiem, S.: Soil moisture retrieval from AMSR-E, IEEE T. Geosci. Remote, 41, 215-229, 2003.

Ntelekos, A., Georgakakos, K., and Krajewski, W.: On the Uncertainties of Flash Flood Guidance: Toward Probabilistic Forecasting of Flash Floods, J. Hydrometeorol., 7, 271-285, 2006.

Parajka, J., Naeimi, V., Blöschl, G., Wagner, W., Merz, R., and Scipal, K.: Assimilating scatterometer soil moisture data into conceptual hydrologic models at the regional scale, Hydrol. Earth Syst. Sci., 10, 353-368, 2006, http://www.hydrol-earth-syst-sci.net/10/353/2006/.

Pegram, G. G. S.: A continuous streamflow model, J. Hydrol., 47, 65-89, 1980.

Pfeffer, J.: Evaluation of remote sensing soil water products by intercomparison over South Africa, Master's thesis, Sciences de la Terre, de l'Univers et de l'Environnement, Université Joseph Fourier de Grenoble, France, 2008.
Savage, M.: Estimation of evaporation using a dual-beam surface layer scintillometer and component energy balance measurements, Agr. Forest Meteorol., 149, 501-517, 2009.

Savage, M., Everson, C., and Metelerkamp, B.: Bowen ratio evaporation measurement in a remote montane grassland: Data integrity and fluxes, J. Hydrol., 376, 249-260, 2009.

Scipal, K., Scheffler, C., and Wagner, W.: Soil moisture-runoff relation at the catchment scale as observed with coarse resolution microwave remote sensing, Hydrol. Earth Syst. Sci., 9, 173-183, 2005 , http://www.hydrol-earth-syst-sci.net/9/173/2005/.

Sinclair, S. and Pegram, G.: Combining radar and rain gauge rainfall estimates using conditional merging, Atmos. Sci. Let., 6, 19-22, 2005.

Su, Z.: The Surface Energy Balance System (SEBS) for estimation of turbulent heat fluxes, Hydrol. Earth Syst. Sci., 6, 85-100, 2002, http://www.hydrol-earth-syst-sci.net/6/85/2002/.

Tasumi, M., Allen, R., Trezza, R., and Wright, J.: Satellite-Based Energy Balance to Assess Within-Population Variance of Crop Coefficient Curves, J. Irrig. Drain. E.-ASCE, 131, 94-109, 2005.

Villarini, G., Krajewski, W. F., and Smith J. A.: New paradigm for statistical validation of satellite precipitation estimates: Application to a large sample of the TMPA 0.25 3-hourly estimates over Oklahoma , J. Geophys. Res., 114, D12106, doi:10.1029/2008JD011475, 2009.

Vischel, T., Pegram, G., Sinclair, S., and Parak, M.: Implementation of the TOPKAPI model in South Africa: Initial results from the Liebenbergsvlei catchment, Water SA, 34, 1-12, 2008a.

Vischel, T., Pegram, G. G. S., Sinclair, S., Wagner, W., and Bartsch, A.: Comparison of soil moisture fields estimated by catchment modelling and remote sensing: a case study in South Africa, Hydrol. Earth Syst. Sci., 12, 751-767, 2008, http://www.hydrol-earth-syst-sci.net/12/751/2008/.b.

Wagner, W., Lemoine, G., and Rott, H.: A Method for Estimating Soil Moisture from ERS Scatterometer and Soil Data, Remote Sens. Environ., 70, 191-207, 1999.

Wagner, W., Bloschl, G., Pampaloni, P., Calvet, J.-C., Bizzarri, B., Wigneron, J.-P., and Kerr, Y.: Operational readiness of microwave remote sensing of soil moisture for hydrologic applications, Nord. Hydrol., 38, 1-20, 2007. 